\title{
What Is Thinking with Images?
}

\author{
Piotr Kozak \\ University of Białystok \\ piotr.kozakl@gmail.com
}

\author{
Krystyna Bielecka \\ University of Warsaw
}

\author{
Jakub R. Matyja \\ SWPS University
}

Received 23 October 2019; accepted 30 October 2019; published 27 December 2019

\section{Introduction}

When one calculates whether a table will fit into the space between a wall and a cupboard, it is likely that a calculation of this sort will be carried out by forming a mental image of the table, the wall, and the cupboard. If I think about my beloved, it is quite plausible that I will bring up a mental image of the one I love.

Similar operations could be conducted in extramental images as well. If an architect designs a house, then he or she will design the house with the help of drawings. If an engineer wants to build a motor engine, he or she will start with a blueprint of the motor engine. If one tries to get from a point $\mathrm{A}$ to a point $\mathrm{B}$, one can use a map. If I want to present an argument in court that John killed Marry, then, if I possess one, I can point at a photograph that represents John killing Marry. All of these examples are instantiations of what can be called "thinking with images." Listing examples of this is an easy task. The hard task, however, is to say exactly what "thinking with images" might be.

Problems arise right from the outset. Even though, it is good scientific practice to start with a precise definition of the subject in question and from a precise definition of the concepts we use. In the case of thinking with images, these are preposterous postulates. For we do not precisely know what images are, nor what thinking is, or even what relation "thinking with" has with these.

Let us start with a definition of an image. In order not to exclude too much phenomena at the beginning of the inquiry, the relevant definition of an image should be as broad as possible. Despite the fact that it may seem that defining an image traditionally as a representation resembling the represented object ${ }^{1}$ is a good starting point, the definition is too ambiguous and uninformative. On the one hand this definition would be too narrow, since it seems not to include diagrammatic representations, like pie-charts, and iconic

\footnotetext{
${ }^{1}$ Etymologically, the term image comes from Latin term imago which means a copy, a likeness.
} 
representations of fictional objects. It would be uninformative, since without defining the concept of resemblance, we cannot determine what kind of relation it is: either it is a relation of sharing common properties, or optical similarity, or a relation of sharing a common structure, etc. Moreover, this definition would determine the form of the relation between representation and the object being represented in advance; the relation, which is to be determined in further investigations.

We cannot define images as visual representations of objects, as well, since this definition would be both too narrow and too broad. It would be too narrow, because it seems that we can have, for example, tactile, ${ }^{2}$ haptic, ${ }^{3}$ olfactory, ${ }^{4}$ gustatory,${ }^{5}$ or auditory images, ${ }^{6}$ which are just as common and just as psychologically important as visual ones (Newton, 1982). It would be too broad, because sentential representations are also visual.

We cannot start from a definition of an image as a modally specific structure preserving representation naturally connected with the object represented (Kulvicki, 2014), as well. Even if it is exhaustive and, ultimately, worth adopting, it would demand that we provide an explanation of what the structure preserving representation is, and what the natural relation between representation and an object being represented is. Without that, at this stage, this definition does not seem to be helpful.

One of the consequences of this lack of a clear definition of an image is that it is hard to tell what a mental image could be. Undoubtedly, both mental and extramental images, despite the obvious differences between them, share some non-trivial properties. On the one hand, it would be hard to understand the concept of a mental image if it had nothing in common with the concept of an image. On the other, understanding an image involves the ability to form a mental image, for example, to know how to construct a triangle on a sheet of paper is to know how to construct a triangle in the mind. This means that, depending on where we start, we need such a definition of a mental image that is in accord with our general understanding of what an image could be, and such a definition of an image that covers the case of mental images.

Yet, in the case of the definition of a mental image, it seems that we are as helpless as in the case of the definition of an image. Interpreting mental images as quasi-perceptual experiences, such as a picture-like or sound-like experience, seems to be uncontroversial, but at the same time uninformative, since it does not settle what kind of representation, if any, gives rise to this sort of experience. Adopting a definition of the term "mental image" denoting the internal representations involved in mental imagery (Block, 1981) is a circular fallacy, since we usually define "mental imagery" with the help of the term "mental image."

\footnotetext{
${ }^{2}$ See, e.g., Lopes, 1997; Kulvicki, 2006; Yoo, Freeman, McCarthy, \& Jolesz, 2003.

${ }^{3}$ See, e.g., Klatzky, Lederman, \& Matula, 1991.

${ }^{4}$ See, e.g., Bensafi et al., 2003; Djordjevic, Zatorre, Petrides, \& Jones-Gotman, 2004; Djordjevic, Zatorre, Petrides, Boyle, \& Jones-Gotman, 2005.

${ }^{5}$ See, e.g., Kobayashi et al., 2004.

${ }^{6}$ See, e.g., Reisberg, 1992.
} 
Defining mental images in terms of quasi-perceptual representations resembling the perceptual experience when the experienced object or an event are not present (Finke, 1989; Thomas, 2003) will not do. For it is underinformative and it shares the same problems with the concept of resemblance as in the case of the definition of an image (Schwartz, 1981). In order not to exclude other modalities, we could use the term "mental image" to refer to any instance of imagining something, which includes more than mental pictures or sounds (Newton, 1993). In this case, one has a mental image, if, for example, one imagines what it would be like to move one's body in a certain way, or what it would feel like if one was to grasp or throw an object. Even though this definition is broad, it is also uninformative, since it gives no suggestion of how to distinguish acts of imagining from other non-imagistic acts of imagination, such as when I imagine that I am a president of the United States.

At this point, what is available is only a contextual definition pointing to paradigmatic examples of the use of the concept of an image of the following kind: we use the concept of an image in the context of the acts of imagining, drawing, painting, or photographing. The acts of imagining and sound-like, or picture-like experiences, etc., cover the case of mental images. Pictures such as drawings, paintings, and photographs cover paradigmatic examples of extramental visual representations. We can speak about tactile, olfactory, or auditory images, etc., and therefore we should include the non-visual examples of images, too. Diagrams are images representing logical relations. In a broad context, even language can be interpreted in pictorial terms, ${ }^{7}$ if only we agree that, for instance, visual metaphors can be interpreted as literary images or as a part of a literary image ${ }^{8}$ For all these examples, we reserve here the term image or iconic representation. ${ }^{9}$

When it comes to the definition of thought there is an even bigger problem. We could say that thought is a product of the operation of thinking, but it would lead us nowhere, if we did not have a comprehensible definition of thinking. Surely, not every mental activity can be called thinking, but that gives us only a partial negative description.

Thinking about thinking in terms of building cognitive models of the world cannot be a starting point, if we do not provide a clear-cut explanation of what a model is. For example, if we understand a model as a set of propositions about the modelled object, then it is hard to tell what kind of model of the world, in terms of a set of propositions, I produce when I am construing a triangle on a sheet of paper, granted that an act of geometrical construction is not some kind of thoughtless activity. ${ }^{10}$

\footnotetext{
${ }^{7}$ On the iconicity of language see, e.g., Dingemanse, Blasi, Lupyan, Christiansen, \& Monaghan, 2015; Fischer, 2004; Sonesson, 2008.

${ }^{8}$ See, e.g., Collins, 1991; Scarry, 1999; Troscianko, 2010, 2013, 2014.

${ }^{9}$ It is worth noting that the listed examples of images are included in Charles S. Peirce's (1982) definition of an icon. Yet, it does not follow that we accept Peirce's definition of an icon here.

${ }^{10}$ It may seem that thoughts are inherently mental acts conducted, speaking metaphorically, "inside" the mind. This is, however, a mistake since it is nonsense to ask where is the thought. Thus, for the operation to be thoughtful does not seem to matter whether it is conducted inside or outside the mind.
} 
An operation of thinking could be seen as a form of manipulating information, but such a definition would be too broad, since even an act of a passive perception may be interpreted as a manipulation of information. Interpreting the act of thinking in terms of propositional attitudes is too narrow, since it is not clear what kind of, if any, propositional attitude I adopt when I imagine a square or when I think about my beloved ones. A rather technical definition of the process of thinking as a syntactical operation on mental symbols would be too restrictive, since it would force us to accept some sort of the language of thought hypothesis in advance.

And yet, although there is no broad consensus on what the operation of thinking really is, it is relatively easy to list unambiguous examples of thinking processes, such as imagining, problem solving, making decisions, understanding, classifying, constructing theories, judging, designing, reasoning, forming hypotheses, or evaluating. Thinking processes are also involved in thoughtful actions such as calculating, testing hypotheses, navigating with a map, making scripts, plans and notes, or playing chess. For all these different cognitive activities, we reserve here the term thinking.

Last but not least, the expression "thinking with images" does not settle what the relation "thinking with" refers to. First, it may express the claim that images determine the content of thought and organize the process of thought, in the same way that one may claim that language determines the content of thought. It means that images are primary in relation to thought processes. In other words, the proficiency in using images influences the way we perceive and think about the world. The main point of inquiry here is to determine the way images can shape our thought processes.

Second, it can mean that the format of thought is imagistic, that is, that the nature of the medium of representation is imagistic by nature. It means that the main point of consideration is the empirical nature of the bearer of thought.

Third, it can refer to the claim that an image is a tool for expressing the content of thought. On the one hand, it means that the thought is ontologically independent from images. On the other, it means the nature of the tool constrains possible thought operations that can be conducted with the help of it, in the same way as the nature of the hammer determines the ways the hammer can be used. As a consequence, we can study either the advantages and constraints imposed by the use of imagistic tools in thinking, or a relation between the use of images and non-imagistic representations, such as words, that is, we can be interested in how and to what extent the use of images differs from the use of words in the process of thinking.

Nevertheless, regardless of the way we decide to interpret the relation thinking with, it seems that one point raises no doubt. It seems reasonable to assume that studying the nature of images and imagistic forms of thought can teach us something important about the latter, in the same way as studying the nature of language reveals something on the nature of thinking. The only difference is that although there is a well-established tradition in studying the processes of thought through studying the nature of language, the same analysis in the case of images are relatively unadvanced. In other words, we know much more 
about language than about images and, consequently, about thinking with language than about thinking with images. A collection of papers below take a step toward changing this.

\section{Do We Think with Images? Between Iconophilia and Iconophobia}

If it just happens that someone asks a philosopher about the relationship status of thoughts and images, the best answer they can give is: "it is complicated." It means that since the very beginning of philosophy we have been stuck in an ongoing ambiguous state with a constant feeling of dissatisfaction with an existing relationship: between a love affair, an outright rejection, and a yearning for a longstanding but past romance.

This general feeling of dissatisfaction comes from a transhistorical struggle between those who can be called here - without any ambition to define these terms explicitly, and being in some sort of slogan form rather than in definable terms - philosophical iconophobes and philosophical iconophiles. What I mean by that may be contextually explained as follows. Among the philosophers-iconophiles, it has been generally held, that thought processes are based on a sequence of mental or extramental images suggesting some ideas or conclusions ${ }^{11}$. To put it generally, it has been claimed that images (or iconic representations in general) play an essential part in what is broadly called thinking and that we cannot explain the psychological mechanism of the process of thinking, as well as the epistemological and metaphysical nature of thoughts, or at least some essentially imagistic kinds of mechanisms and thoughts, without referring to some sort of mental or extramental images responsible for representing the objects of our thoughts. In a nutshell, a philosophical iconophile assumes that it is the case that we think, or that we can think in or with images. What does it mean?

Philosophers-iconophiles may defend the following four particular claims conjunctly or separately. First, it may be held that the nature of thinking, or at least some thought processes, consists largely in manipulating (mental) images of objects. Images can be seen here as the building blocks of thoughts, that is, they are a basic element of any thought and a metaphysical foundation of any thoughtful cognitive act. From this perspective, every complex thought is a structure made of imagistic "atoms." Second, interactions between (some) thoughts is most likely based on some sort of, assumingly associative, relations between images. It means that thought acts have an imagistic syntax, that is, the relations between (some) thoughts could be described in terms of a relation between images. Third, there is a special kind of imagistic semantic relation, non-reducible to other forms, especially sentential forms, that characterize the way our thoughts refer to the world. It means that the relation between images and the world is not mediated by any non-imagistic representation and, what follows, images and imagistic thoughts refer to the world directly. Fourth, there is a special kind of knowledge we have access to by means of manipulating

\footnotetext{
${ }^{11}$ As it was summed up sloganistically by Rudolf Arnheim (1969), "thinking calls for images, and images contain thought" (p. 254).
} 
images. It means that images and imagistic thinking ${ }^{12}$ may provide information that is not possible to get by any other than imagistic representation.

Thus, images are basic units of some thought processes, there is an imagistic form of syntactical relation between thoughts, and there is a kind of imagistic form of a semantic and epistemic relation between thoughts and the world. Let us call this general view the imagistic view on the nature of thought and thinking, or simply the imagistic view, and the proponents of the imagistic view-iconophiles. Accordingly, those who consider the imagistic view as absurd may be called iconophobes.

Although iconophilia is traditionally ascribed to British Empiricists ${ }^{13}$, it is in fact as old as philosophy itself, and is rooted in the psychological ideas of Aristotle and Thomas Aquinas, who assumed that images are metaphysically and epistemologically basic for all our mental operations. For the first, images are the essential intermediary between perception and thinking. In his own words, "the soul never thinks without a phantasma" (Aristotle, 1994, 431a16-431a17). For the second, operating with images is crucial for any act of understanding (Aquinas, 1920) ${ }^{14}$. Rudolf Arnheim (1969), Lawrence Barsalou (1999, 2010) ${ }^{15}$, Ralph Ellis (1995), Mark Johnson (1987), Susanne Langer (1976), Natika Newton (1993), Jesse Prinz (2002), Eleanor Rosch (1975), and Edward B. Titchener (1909) can be considered as exemplary $20^{\text {th }}$-century representatives of this view.

\footnotetext{
12 Although "imagistic thinking" is used relatively rarely in contemporary literature (however, see, e.g., Gauker, 2011; Botterill \& Carruthers, 1999), I would prefer the use of the term "imagistic" rather than, the more commonly used, "visual" or "picture" thinking. It is important, since the former does not suggest the intellectual aspect of perception issue that visual thinking does and does not reduce investigations to picture-like objects as in the case of "picture thinking."

${ }^{13}$ Historically speaking, there is controversy about who in fact represents the view. Assumingly Berkeley believes that all ideas are images (the opposite view see, e.g., Kasem, 1989). Similarly, but not without doubts (e.g., Yolton, 1996), believes Hume. The case of Locke's view is far from being clear. It can be argued that we do not have to refer to images to understand the nature of Locke's concept of idea and we can develop an adverbial strategy of interpretation. See, for example, Ayers, 1991; Chappell, 1994; Lowe, 1995; Soles, 1999; White, 1990; Yolton, 1996.

14 "Everyone can experience within oneself that when one tries to understand something, one forms certain phantasms for oneself by way of examples, in which one examines, as it were, the thing one is striving to understand. And so it is that when we wish to make someone else understand a thing, we propose examples to him, through which he can form phantasms for himself in order to understand" (Aquinas, 1920, 84.7 c37-43).

${ }^{15}$ Note that if the notion of an image is understood loosely as a modally specific structure preserving representation naturally connected with the object represented (Kulvicki, 2014) and the term "mental image" refers to every imaginary schema of the form: "what it would be like to" (Newton, 1993), then as representatives of the imagistic view may be classified also by philosophers and scientists who do not directly refer to images, but instead indicate the role of a perceptual symbol system, in particular (Barsalou, 1999), or modally specific conceptual representations (Prinz, 2002), in general. Accordingly, the works of Robert Cummins $(1989,1996)$ can be interpreted, at least partly, as representing the imagistic view, since he acknowledged the role of structural representations which is an application of Shepard's (Shepard \& Chipman, 1970) concept of second-order isomorphism and a generalization of the concept of diagrammatic representation.
} 
A scepticism towards the imagistic view has been accompanying philosophy from its very beginning as well. Arguably, the first iconophobe was Plato for whom images and imagination held a lowly position, for images were only copies of things that are themselves copies. For Plato, the image producer merely mimics the logos, expressible aptly only by means of the discursive train of thought (Plato, 1997, 39b). So, it is not surprising, that for Plato $(1997,511 \mathrm{c})$ the images are only epiphenomena and play only an incidental role in thinking. The latter is a matter of being guided by pure ideas and ending with ideas. Max Bennet and Peter M. S. Hacker (2003), George Botterill and Peter Carruthers (1999), Patricia Churchland (1986), Paul Churchland (1979), Donald Davidson (1982), Daniel Dennett (1991), Michael Devitt (2006), Gottlob Frege (1918-1919/1952), Zenon Pylyshyn (1973; 2003a), Georges Rey (1981), Richard Rorty (1965), Gilbert Ryle (1949), Moritz Schlick (1918), Wilfrid Sellars (1968), and John Watson (1913; 1928) have followed, although for different reasons, the iconophobic path of Plato. According to this view, images that occur during the thought process play the same role as illustrations in a textbook. They are neither necessary nor sufficient for thinking and are only epiphenomena of the inferential operations and logical processing of information that are the basis of every thought process.

Between the extremes of iconophobia and iconophilia there are, of course, intermediate positions which hold that neither mental images nor abstract rules of inference are more basic then the other. It is rather the case that these two kinds of processes are logically and metaphysically independent, though often interrelated. Neither are inferential processes based on images, nor are images the result of applying abstract rules of inference. Examples of such approach can be found in the writings of Ned Block (1983), Tyler Burge (2010), Michel Denis (1991), Jerry Fodor (1975), Christopher Gauker (2011), Philip Johnson-Laird (1993, 1994), Stephen Kosslyn (1980, 1994), Jill Larkin and Herbert A. Simon (1987), Allan Paivio (1971, 1986, 2007), Henry Habberley Price (1951-1952, 1953), Bertrand Russell (1921), Klaus Sachs-Hombach (2003), Robert Schwartz (1981), Roger Shepard and Jacqueline Metzler (1971), Paul Thagard (2005, 2012), and Barbara Tversky (2011). The cases of Kosslyn and Johnson-Laird are paradigmatic. According to Kosslyn, although imagery is essential for performing spatial and perceptual tasks, it is not necessary for all thought processes. For example, it is not necessary for deductive inferences. It is not even the case that, according to Kosslyn, we can construct autonomous semantics for mental images, since the content of the latter is determined by a set of logical functions being a part of a visual buffer. Johnson-Laird also remains neutral regarding to what extent reasoning relays on mental imagery. Although mental models can be realized in the form of mental images, they could be realized in some other way, as well. Mental models are not images, though they can take an imagistic form.

Nevertheless, for the purposes of the present text, historical issues that may be raised are relatively unimportant. That is, it is not the point here, to classify one or another philosophical view into a certain side of a dispute; classifying views according to a certain -izm can at best deliver a seeming explanation, but in fact always leaves us none the wiser. To get a profound philosophical understanding of any classified issue one needs to get, to put it broadly, a deep understanding of the principle of classification. That is, one needs to 
fully understand the subject of the dispute, the intuitions that support certain views, and the philosophical reasons that one might have for adopting the latter. For it seems that the discussion between iconophiles and iconophobes tends to be a discussion on an obscure subject. What we do hope to achieve here is a relative clarity regarding the nature of the issue and the stake of the debate. It is a necessary step, if we want to move forward and discuss the role images play in thinking.

\section{Why Do We Think that We Think with Images?}

At first glance, it seems that there is nothing wrong with the imagistic view, for the claim that we can think with images sounds natural and intuitive. It is also popularized in culture in a number of materials devoted to visual thinking and visual learning. Nevertheless, as it frequently happens, this prescientific intuitiveness is both the cause of a continuous attachment to the imagistic view, as well as the main source of a conceptual confusion. As an example, it is argued that conflicting intuitions regarding the nature of mental images may be one of the causes of incompatible data in the imagery debate (see, e.g., Reisberg, Pearson, \& Kosslyn, 2003; Berman, 2008).

The intuitive character of the imagistic view seems to have two prescientific sources. The first is based on a general observation that images play an important role in a number of cognitive activities. On a daily basis images are being used in mathematics, geometry, science, and the arts. Images are widespread in school textbooks and in educational practice and they are common in research experience in our attempts to make discoveries and to construct proof or definitions. We visualize our thoughts with gestures; in a daily praxis, images are held to be the basis of the most common form of practical reasoning, such as: "If I make a move like so [image], then I shall be able to do so [image]." Images are indispensable in the case of understanding manual instructions of using a device. Showing how things work or how they can be constructed is much more informative than trying to explain it verbally or using abstract symbols. ${ }^{16}$ In fact, it is hard to imagine how the known world would look if there were no pictures at all. For example, what would the world look like without maps $?^{17}$ Therefore, as it is held, it is the case that we think in images, since without it, there would be no possible explanation of all these different cognitive activities.

\footnotetext{
${ }^{16}$ In problem solving tasks, participants who built a physical model of a problem are more likely to solve the problem. It includes visualising with the help of graphs, as well with the help of gestures. See, e.g., Bocanegra, Poletiek, Ftitache, \& Clark, 2019; McNeill, 1992; Vallée-Tourangeau, F., Steffensen, Vallée-Tourangeau, G., \& Sirota, 2016.

${ }^{17}$ It is also possible to use pictorial elements for representing abstract ideas, for example, we use dots and lines to show directions on route maps (Tversky \& Lee, 1998, 1999), and lines, boxes (Zacks \& Tversky, 1999), and arrows (Heiser \& Tversky, 2006) to communicate in a number of graphic languages (Tversky 2004). A trivial example of such graphic language is a road sign. For other examples of the cognitive role of images see Donald, 1991; Hutchins, 1995; Kirsh, 1995; Malafouris, 2013; Norman, 1993; Stjernfelt, 2007; Suchman, 1987; Tversky, 2001.
} 
The second source of the intuition supporting the imagistic view concerns the phenomenology of thought and mental images, pointing to the striking similarities between them. On the one hand, introspective reports seem to indicate the iconic nature of some mental operations, such as a mental rotation of spatial figures, imagining myself wearing a moustache, thinking of how to move from a point $\mathrm{A}$ to a point $\mathrm{B}$, etc. This phenomenological intuition is so strong, that, citing Russell (1919),

if you try to persuade an ordinary uneducated person that she cannot call up a visual picture of a friend sitting in a chair, but can only use words describing what such an occurrence would be like, she will conclude that you are mad. (p. 11)

This commonsensical intuition found its early scientific expression in the famous Francis Galton's questionnaire (1880) ${ }^{18}$ on visualizing and other allied activities analyzing, among others, different styles of thinking, and since the beginning of the 60's it has been scientifically expressed in a number of studies on the nature of memory (Paivio, 1963), or research conducted in the mental chronometry paradigm (Shepard \& Metzler, 1971), building what has been commonly called a pictorial approach to the nature of mental images. The latter approach is based on the assumption that, most generally, the "pictorial" features of mental images are responsible for the eventual success of tasks involving mental imagery. For example, since the mid-70s - referring to the results of mental scanning experiments (Kosslyn, Ball, \& Reiser, 1978) and neuroimaging studies (Kosslyn, Thompson, \& Alpert, 1997; Kosslyn, Ganis, \& Thompson, 2001)—Stephen Kosslyn with his collaborators have been claiming that at least some acts of thinking are fundamentally depictive, inasmuch as their nature consists in a spatial structure of the object of thought (Kosslyn, Thompson, \& Ganis, 2006; Pearson, Naselaris, Holmes, \& Kosslyn, 2015).

On the other hand, operations involving mental images seem to share certain phenomenological features with thought processes, broadly conceived. There are at least three phenomenological marks indicating the iconic nature of thought (Wollheim, 1984). First of all, iconic mental states seem to be intentional. That is, that they are of or about something, in the same way that thoughts are intentional in general. A mental image is always an image of something. Similarly, a thought is always a thought about something. A mental image of a cat is about a cat, in the same way as a thought about a cat concerns a cat (Harman, 1998).

Second, the content of mental images seems to be directly accessible, in the same way as, assumingly, we "directly know" what are we thinking about. It means that we do not need to observe our iconic mental states in the same way as we do not need to read or listen to our non-iconic mental states, before we know what they are and what their content is. For example, we do not interpret a series of phonemes heard in our first language in order to

\footnotetext{
${ }^{18}$ Galton's questionnaire has proved to be very influential and has had many followers, including Betts's (1909) Questionnaire upon Mental Imagery (QMI), Gordon's (1949) Test of Visual Imagery Control (TVIC), and Marks's (1973) Vividness of Visual Imagery Questionnaire (VVIQ), even though it seems that it has failed the replication test. See, e.g., Isaac \& Marks, 1994; Brewer \& Schommer-Aikins, 2006.
} 
hear a word. We directly hear the word, granted that we have mastered the language. In the same way, we do not interpret mental images as we know what they mean directly. ${ }^{19}$

Third, it seems reasonable to argue that iconic mental states have a causal efficacy over the behavior and the mental dispositions of the person who has them, in the same way as our thoughts and beliefs can influence other beliefs and actions. My imagining how to get back home can influence my decision regarding what route I choose to get home safely. To sum up, images are not only important for a number of thought processes but also share certain phenomenological features with thinking.

Still, despite how intuitive the imagistic view is, it does not mean that iconophobia is doomed to fail. Even though remarks on phenomenology and the cognitive importance of iconic (mental) representations seem to indicate the correctness of the intuition expressed by the imagistic view, the strength of this intuition is directly proportional to the degree of its unclarity, that is, the intuition is the more convincing, the more unclear it is. On the one hand, both sources of the intuition seem to be fallible. On the other hand, as one might have already noticed, the imagistic view is in fact an umbrella term for a few different claims on the nature of thinking. Although the claim that in some sense we think in images, or that pictures are essential for certain cognitive tasks, is, according to the view presented here, worth defending. The problem arises when one wants to explicate what we really mean when we say that we think in images and what is a satisfactory description of the imagistic view. What is wrong with our intuitions then?

First, the widespread use of images in an obvious way does not imply that we think with images. Granted, in folk psychology, one commonly emphasizes the general importance and the high frequency of the use of non-verbal cognitive tools, such as exercising imagery skills, forming non-verbal instructions in practical reasonings, using visual representations in science, using drawings and diagrams in reasonings, and many others. For example, it may be indicated that we use pictures of objects to memorize the meaning of words, maps to navigate in physical space, drawings to solve geometrical tasks, imagery to think how a certain shape would look from a different angle, etc. As it is claimed, tasks like memorizing, navigating, solving geometrical problems, etc., are cognitive in nature and it is hard, if not impossible, to perform them without iconic representations. This view is commonly shared. Nonetheless, it would be pointless to mention any representatives of such an approach. For it would be hard to deny the empirical fact that we do use (mental) images on a daily basis for specific cognitive and practical purposes.

Considerable worries arise when one tries to accommodate the trivial fact that images play an important role in cognitive practice within philosophical accounts of the nature of thinking. For the fact that one commonly uses images does not follow the conclusion that one

\footnotetext{
${ }^{19}$ Note that the noninterpretative nature of mental images does not mean that we cannot err in grasping the content of mental images. In the same way, even if we do not interpret a series of phonemes in order to hear a word, it does not mean that we cannot be wrong regarding the interpretation of the content of the word, depending on the context or the use of the word.
} 
thinks with images, in the same way that people frequently wave their hands while speaking does not follow that the nature of language is determined by handwaving ${ }^{20}$. Using more direct examples, the empirical observation that we frequently use commas in a written language says nothing on what language is. We frequently use our fingers to count, and still from that very fact nothing follows for the metaphysical nature of calculation which is a matter of an abstract mathematical operation and it is not a matter of its realization in counting on fingers.

Therefore, the intuition is either trivial, or false. Either it says only that we commonly use pictures for cognitive purposes (nobody argues with this) or that from the use of pictures for cognitive operations we can infer the true nature of cognitive operations, which is false. Without establishing what kind of contribution images make to the act of thinking, nothing follows for the nature of the latter.

Second, the phenomenological evidence is not conclusive. On the one hand-which is the basis of Pylyshyn's (1981) early critique of Kosslyn's approach to mental images - even if introspective reports indicate the imagistic nature of such operations as mental rotation, it does not follow that the true nature of thought processes consists in manipulating images. For the phenomenological evidence can teach us at least how things appear to us in conscious experience, but that indicates only the phenomenon that is to be explained, and not a possible explanation of that phenomenon. It means that introspective reports may provide a comprehensive description of an explanandum, but more evidence is needed if one wants to provide an explanans. Analogically, if one provides a full description of the apparent path of the Sun in the Earth's sky, it does not mean that one provides a correct explanation of the Sun's movement. A description of the apparent movement of the Sun is far different from an apt explanation of the fact that the Sun moves in the Earth's sky; or, as Georg Lukacs (1966) once put it vividly, even if we have completed our phenomenological description of the Devil, the question remains unanswered as to whether the Devil actually exists. Likewise, even if some thought processes may appear as if they were imagistic, it does not mean that their real nature is imagistic. It only means that we need an explanation as to why they appear as imagistic.

On the other hand, there is no general consensus regarding a valid phenomenological description of mental images' features. It is neither settled that mental images are intentional, inasmuch as quale are not intentional (Martin, 2008; Wright, 1983); nor do we learn something from mental images and that mental images can contribute to knowledge (Sartre, 1936/1962); nor do they influence our behaviour, rather than being epiphenomena of other, assumingly symbolic processes responsible for this influence (Pylyshyn, 2003a). What is most important, based on a phenomenological description alone, is that we do not have any conceptual tool to determine which description is correct and which is not. The only thing we can do is to toss a coin.

\footnotetext{
${ }^{20}$ Although handwaving can say something about the pragmatics of language, it remains silent when it comes to semantics and syntax.
} 


\section{What Do We Mean When We Ask "What Is Thinking with Images"?}

As I was arguing, the basic prescientific intuitions supposedly being in support of the imagistic view seem to be at least vague and fallible. However, the situation could not be different, since what we certainly lack is a clear understanding of what these intuitions were to support. In other words, it is not clear what we really mean when we say that we think in images (see, e.g., Block, 1981, 1983). As Pylyshyn (2003b, p. 113) aptly noted, despite claims that thoughts have a picture-like format have for a long time persisted, the problem of stating clearly what it means for imagistic thought to be pictorial has been rarely explicitly tackled. Yet the real difficulty is even more deep-seated and lies in the fact that we do not even know what we actually mean by asking the question "what is thinking with images?" and what kind of answer we expect.

One of the first steps we have to take is to avoid the temptation of an easy win. The latter is based on the claim that the very question is absurd, and it is ill-posed. For, as one may argue, it is not the case that we think with images, in the same way as it is not the case that we think with words. We think in thoughts, and not in images, or words, one may say. Although such an answer may seem tempting, it is misleading at best (see, e.g., Putnam, 1975). For no one argues against the claim that we use thoughts to think. Yet to say that we think with thoughts is no more informative than to say that we do not speak in French, or in English, but we use language to speak. In fact, in order to study language, we study particular instantiations of language as such, for example French, or English. The same is in the case of words and images. We can study the nature of thoughts only by means of studying particular instantiations of thinking processes, and, historically speaking, revealing the nature of thought was the primary reason for philosophers' interest in language. In other words, even if a philosopher poses a question, for example, on the nature of syntax in language, their main point of concern is the structure of thinking, granted that thinking processes reveal their structure in language. The same can be claimed in the case of the use of images. Asking how we use images in the context of thought processes is asking what it says about the nature of the thoughts. Therefore, the stake of the question "what is thinking with images?" is a general problem of the nature of thinking.

The second necessary step for understanding the question is to clearly distinguish between different understandings of the latter. If we ask what is thinking with images, we may have questions in mind such as: What sort of things might imagistic thoughts be? Can imagistic thoughts be a form of beliefs about the way the world is? Can imagistic thoughts be a part of desires, hopes, or fears? How does the imagistic type of thinking relate to other types of thinking, especially to verbal ones? Can images be basic elements of thoughts and if it is so, how can the vocabulary appropriate for describing the nature of thought be accommodated within the description of the nature of images? How can a subject grasp the content of the image in a way that it will influence his or her behaviour? In asking such questions we are asking metaphysical questions on the nature of thinking and on the particular role images play in thought processes. 
On the other hand, when we ask the question: "what is thinking with images?" we may be interested in semantic issues. This type of question relates to the problem of content of imagistic thought, which is the way imagistic thoughts relate to the world. For example, do imagistic thoughts represent the world in a determinate way and do they have determinate content? How do we determine the content of (mental) images? Can we describe the imagistic content in the same way we characterize the language content, and if not, what are the similarities and differences? Is imagistic content propositional or eventually can it be translated into propositional form? Can we use "that"-clauses to specify the content of imagistic thoughts? Is there a distinctive way images and imagistic thoughts represent the world? Do the imagistic thoughts have some sort of internal structure, as in the case of language syntax? Is the imagistic content translatable into a language description? Can images ground the meaning of words? What kind of relation there is between imagistic content and perceptual content?

A third type of question refers to the problem of imagistic knowledge, that is, what and in what way do we learn through (mental) images? In this case, we may ask questions such as: How do we know what the content of imagistic thoughts are? What are the criteria to determine the content of the imagistic thoughts? How can we ascribe possessing imagistic thoughts to others? Do imagistic thoughts contribute to knowledge? Can an imagistic way of acquiring beliefs provide justifications? Can imagistically acquired beliefs be a form of knowledge in the absence of independent non-imagistic grounds? If so, what level of confidence would be rational? Are there any inferential relations between imagistic thoughts, and if so, is there any kind of logic of images? If thinking with images could be a form of knowledge, then how and to what extent does it differ from non-imagistic forms of knowledge? If imagistic knowledge is as form of knowledge, then if and how does it contribute to scientific knowledge?

The last type of question has an empirical nature and refers to the nature of the format and the mechanism of the imagistic thought. It means that we may be interested in answering such questions as: What is an empirical, for example, neurobiological mechanism of using mental images? What is the empirical nature of mental images? Are they perceptual or propositional in format? How do we perceive images and what is a psychological mechanism responsible for understanding images? How do we learn to interpret and to understand images? In what way does the use of images shapes how we think and reason?

Therefore, when asking the question "what is thinking with images?" the proponents and the opponents of the imagistic view can have different questions in mind and even if we discuss the problem of what is thinking with images, it does not mean that we are discussing the same subject. For example, Larkin and Simon (1987), in their classical study on the nature of diagrammatic reasoning, are concerned primarily with epistemological questions. The imagery debate relates in most cases to the nature of the mental images format, yet the most severe criticism of the pictorial view on the nature of the latter is formulated from semantical standpoints, as in the case of Pylyshyn (2003a). The early critique of imagistic mental representations by Fodor (1975) concerns mostly the metaphysical nature 
of thoughts and images. Wittgenstein's (1953) and Dennett's (1991) arguments against the imagistic view are a bundle of semantical and metaphysical claims. Moreover, it is possible to defend the imagistic view from empirical standpoint, while partly rejecting it on metaphysical and semantical grounds as in the case of Kosslyn's (1980) quasi-pictorial view. As another example, Larkin and Simon (1987) defend the imagistic view from the epistemological standpoint, but it is not settled whether they would agree with metaphysical or semantical claims.

Yet, it seems quite clear that a full-blooded theory of imagistic thinking should cover all four types of questions. For it is impossible to maintain the epistemological standpoint while rejecting the metaphysical one, or to have a theory of content that gives no conceptual possibility to answer the question not to determine the content of imagistic representation. Finally, we could not have any plausible answer for the metaphysical, semantical, or epistemological question, if it was in contradiction with empirical findings on the format of imagistic representations. Therefore, if one wants to defend the imagistic view, one has to find plausible answers to the questions: What does it mean that images are the building blocks of thinking? What is imagistic content and how it is determined? What do we learn from images and is there any logic to images? Granted that all these answers are in accord with our empirical knowledge on the nature of the thought format. We hope that the collection of papers presented here will help to make a step forward in finding credible answers to all these questions.

This work was supported by the research grant "What is Thinking with Images?", SO-

NATA 10, granted by the National Science Centre, Poland, on the basis of the decision No. 2015/19/D/HS1/02426.

\section{References}

Aquinas, T. (1920). Summa Theologiae, Part 1. trans. Fathers of the English Dominican Province. London, UK: Burns, Oates \& Washbourne.

Aristotle. (1994). Aristotle's De anima. Leiden, the Netherlands: E.J. Brill.

Arnheim, R. (1969). Visual Thinking. Berkeley: University of California Press.

Ayers, M. (1991). Locke: Epistemology and Ontology. London, UK: Routledge.

Barsalou, L.W. (1999). Perceptual Symbol Systems (with commentaries and author's reply). Behavioral and Brain Sciences, 22, 577-660. https://doi.org/10.1017/S0140525X99002149

Barsalou, L.W. (2010). Grounded cognition: Past, present, and future. Topics in Cognitive Science, 2, 716-724. https://doi.org/10.1111/j.1756-8765.2010.01115.x

Bennett, M., \& Hacker, P. (2003). Philosophical Foundations of Neuroscience. Oxford, UK: Blackwell. 
Bensafi, M., Porter, J., Pouliot, S., Mainland, J., Johnson, B., Zelano, C., ..., Sobel, N. (2003). Olfactomotor Activity During Imagery Mimics that During Perception. Nature Neuroscience, 6(11), 1142-1144. https://doi.org/10.1038/nn1145

Berman, D. (2008). A confession of images. Philosophical Practice, 3, 255-266.

Block, N. (1981). Introduction: What Is the Issue? In N. Block (Ed.), Imagery (pp. 1-18). Cambridge, MA: MIT Press.

Block, N. (1983). Mental Pictures and Cognitive Science. The Philosophical Review, 92(4), 499-541. https://doi.org/10.2307/2184879

Bocanegra, B. R., Poletiek, F. H., Ftitache, B., \& Clark, A. (2019). Intelligent problem-solvers externalize cognitive operations. Nature Human Behaviour, 3, 136-142. https://doi.org/10.1038/s41562-018-0509-y

Botterill, G., \& Carruthers, P. (1999). The Philosophy of Psychology. Cambridge, UK: Cambridge University Press. https://doi.org/10.1017/CBO9780511612428

Burge, T. (2010). The Origins of Objectivity. Oxford, UK: Oxford University Press. https://doi.org/10.1093/acprof:oso/9780199581405.001.0001

Chappell, V. (1994). Locke's Theory of Ideas. In V. Chappell (Ed.), The Cambridge Companion to Locke (pp. 26-55). Cambridge, UK: Cambridge University Press. https://doi.org/10.1017/CCOL0521383714.003

Churchland, P. M. (1979). Scientific Realism and the Plasticity of Mind. Cambridge, UK: Cambridge University Press. https://doi.org/10.1017/CBO9780511625435

Churchland, P. S. (1986). Neurophilosophy. Cambridge, MA: MIT Press.

Collins, C. (1991). The Poetics of the Mind's Eye: Literature and the Psychology of Imagination. Philadelphia: University of Pennsylvania Press.

Davidson, D. (1982). Rational Animals. Dialectica, 36(4), 317-327. https://doi.org/10.1111/j.1746-8361.1982.tb01546.x

Denis, M. (1991). Imagery and Thinking. In C. Cornoldi \& M. McCaniel (Ed.), Imagery and Cognition (pp. 103-131). New York, NY: Springer Verlag. https://doi.org/10.1007/978-1-46846407-8_4

Dennett, D. (1991). Consciousness Explained. Boston, MA: Little, Brown.

Devitt, M. (2006). Ignorance of Language. Oxford, UK: Oxford University Press. https://doi.org/10.1093/0199250960.001.0001

Dingemanse, M., Blasi, D. E., Lupyan, G., Christiansen, M. H., \& P. Monaghan (2015). Arbitrariness, Iconicity, and Systematicity in Language. Trends in Cognitive Sciences, 19(10), 603-615. https://doi.org/10.1016/j.tics.2015.07.013

Djordjevic, J., Zatorre, R. J., Petrides, M., Boyle, J. A., \& Jones-Gotman, M. (2005). Functional Neuroimaging of Odor Imagery. Neuroimage, 24, 791-801. https://doi.org/10.1016/j.neuroimage.2004.09.035 
Djordjevic, J., Zatorre, R. J., Petrides, M., \& Jones-Gotman, M. (2004). The Mind's Nose: Effects of Odor and Visual Imagery on Odor Detection. Psychological Science, 15(3), 143-148. https://doi.org/10.1111/j.0956-7976.2004.01503001.x

Donald, M. (1991). Origins of the modern mind. Cambridge, MA: Harvard University Press.

Ellis, R. D. (1995). Questioning Consciousness: The Interplay of Imagery, Cognition, and Emotion in the Human Brain. Amsterdam, the Netherlands: John Benjamins. https://doi.org/10.1075/aicr.2

Fodor, J. (1975). The Language of Thought. Cambridge, MA: Harvard University Press.

Frege, G. (1918-1919). The Thought: A Logical Inquiry. Mind, 55(259), 289-311. (Original work published 1956). https://doi.org/10.1093/mind/65.1.289

Finke, R. A. (1989). Principles of Mental Imagery. Cambridge, MA: MIT Press.

Fischer, O. (2004). Evidence for Iconicity in Language. Logos and Language: Journal of General Linguistics and Language Theory, 5(1), 1-19.

Gauker, C. (2011). Words and Images. An Essay on the Origin of Ideas. Oxford, UK: Oxford University Press. https://doi.org/10.1093/acprof:oso/9780199599462.001.0001

Harman, G. (1998). Intentionality. In W. Bechtel \& G. Graham (Ed.), A Companion to Cognitive Science (pp. 602-610). Oxford, UK: Blackwell. https://doi.org/10.1002/9781405164535.ch47

Heiser, J., \& Tversky, B. (2006). Arrows in comprehending and producing mechanical diagrams. Cognitive Science, 30, 581-592. https://doi.org/10.1207/s15516709cog0000_70

Hutchins, E. (1995). Cognition in the wild. Cambridge, MA: MIT Press.

Johnson, M. (1987). The Body in the Mind. Chicago, IL: University of Chicago Press. https://doi.org/10.7208/chicago/9780226177847.001.0001

Johnson-Laird, P. (1993). Human and Machine Thinking. Hillsdale, NJ: Erlbaum.

Johnson-Laird, P. (1994). Mental models and probabilistic thinking. Cognition, 50, 189-209. https://doi.org/10.1016/0010-0277(94)90028-0

Kasem, A. (1989). Can Berkeley Be Called an Imagist? Indian Philosophical Quarterly, 6, 75-88.

Klatzky, R. L., Lederman, S. J., \& Matula D. E. (1991). Imagined Haptic Exploration in Judgements of Object Properties. Journal of Experimental Psychology: Learning, Memory, and Cognition, 17, 314-322. https://doi.org/10.1037/0278-7393.17.2.314

Kobayashi, M., Takeda, M., Hattori, N., Fukunaga, M., Sasabe, T., Inoue, N. ... Watanabe, Y. (2004). Functional Imaging of Gustatory Perception and Imagery: “Top-Down” Processing of Gustatory Signals. NeuroImage, 23, 1271-1282. https://doi.org/10.1016/j.neuroimage.2004.08.002

Kosslyn, S. M. (1980). Image and Mind. Cambridge, MA: Harvard University Press.

Kosslyn, S. M. (1994). Image and brain: The resolution of the imagery debate. Cambridge, MA: MIT Press. https://doi.org/10.7551/mitpress/3653.001.0001

Kosslyn, S. M., Ball, T. M., \& Reiser, B. J. (1978). Visual images preserve metric spatial information: evidence from studies of image scanning. Journal of Experimental Psychology: Human Perception and Performance, 4, 47-60. https://doi.org/10.1037/0096-1523.4.1.47 
Kosslyn, S. M., Ganis, G., \& Thompson, W. (2001). Neural foundations of imagery. Nature Reviews Neuroscience, 2, 635-642. https://doi.org/10.1038/35090055

Kosslyn, S. M., Thompson, W., \& Alpert, N. (1997). Neural systems shared by visual imagery and visual perception: a positron emission tomography study. Neuroimage, 6, 320-334. https://doi.org/10.1006/nimg.1997.0295

Kosslyn, S. M., Thompson, W. L., \& Ganis, G. (2006). The Case for Mental Imagery. Oxford, UK: Oxford University Press. https://doi.org/10.1093/acprof:oso/9780195179088.001.0001

Kulvicki, J. (2006). Pictorial Representation. Philosophy Compass, 1(6), 535-546. https://doi.org/10.1111/j.1747-9991.2006.00036.x

Kulvicki, J. (2014). Images. New York, NY: Routledge. https://doi.org/10.4324/9781315884578

Langer, S. K. (1976). Philosophy in a New Key. Cambridge, MA: Harvard University Press.

Larkin, J. H., \& Simon, H. A. (1987). Why a diagram is (sometimes) worth ten thousand words. Cognitive Science, 11, 65-99. https://doi.org/10.1111/j.1551-6708.1987.tb00863.x

Lopes, D. M. (1997). Art Media and the Sense Modalities: Tactile Pictures. The Philosophical Quarterly, 47, 425-440. https://doi.org/10.1111/1467-9213.00069

Lowe, E. J. (1995). Locke on Human Understanding. London, UK: Routledge.

Lukacs, G. (1966). Existentialism or Marxism. In G. Novak (Ed.), Existentialism versus Marxism (pp. 134-153). New York, NY: Delta Press.

Malafouris, L. (2013). How things shape the mind: A theory of material engagement. Cambridge, MA: MIT Press. https://doi.org/10.7551/mitpress/9476.001.0001

Martin, C. B. (2008). The Mind in Nature. Oxford, UK: Oxford University Press.

McNeill, D. (1992). Hand in Mind: What Gestures Reveal about Thought. Chicago, IL: Chicago University Press.

Newton, N. (1982). Experience and Imagery. The Southern Journal of Philosophy, 21, 475-487. https://doi.org/10.1111/j.2041-6962.1982.tb00314.x

Newton, N. (1993). The sensorimotor theory of cognition. Pragmatics and Cognition, 1, 267-305. https://doi.org/10.1075/pc.1.2.04new

Norman, D. A. (1993). Things that make us smart. Reading, MA: Addison-Wesley.

Pearson, J., Naselaris, T., Holmes, E. A., \& Kosslyn, S. M. (2015). Mental imagery: Functional mechanisms and clinical applications. Trends in Cognitive Sciences, 19(10), 590-602. https://doi.org/10.1016/j.tics.2015.08.003

Paivio, A. (1963). Learning of adjective-noun paired associates as a function of adjective-noun word order and noun abstractness. Canadian Journal of Psychology, 17, 370-379. https://doi.org/10.1037/h0083277

Paivio, A (1971). Imagery and verbal processes. New York, NY: Holt, Rinehart, and Winston.

Paivio, A (1986). Mental representations: A dual coding approach. Oxford, UK: Oxford University Press. 
Paivio, A. (2007). Mind and Its Evolution: A Dual Coding Theoretical Approach. Mahwah, NJ: Erlbaum.

Peirce, C. S. (1982) The Writings of Charles S. Peirce: A Chronological Edition (Vol. 1-6). Bloomington: Indiana University Press.

Plato (1997). 'Theaetetus', 'Philebus', and 'Republic' in Plato: Complete Works. (J. M. Cooper \& D. S. Hutchinson, Eds.). Indianapolis, IN: Hackett Publishing.

Price, H. H. (1951-1952). Image Thinking. Proceedings of the Aristotelian Society. New Series, 52, 135-166. https://doi.org/10.1093/aristotelian/52.1.135

Price, H. H. (1953). Thinking and Experience. London, UK: Hutchinson's University Library.

Putnam, H. (1975). Philosophical Papers. Cambridge, UK: Cambridge University Press.

Pylyshyn, Z. W. (1973). What the Mind's Eye Tells the Mind's Brain: A Critique of Mental Imagery. Psychological Bulletin, 80, 1-25. https://doi.org/10.1037/h0034650

Pylyshyn, Z. W. (1981). The imagery debate: Analogue media versus tacit knowledge. Psychological Review, 88(1), 16-45. https://doi.org/10.1037/0033-295X.88.1.16

Pylyshyn, Z. W. (2003a). Seeing and Visualizing: It's Not What You Think. Cambridge, MA: MIT Press. https://doi.org/10.7551/mitpress/6137.001.0001

Pylyshyn, Z. W. (2003b). Return of the mental image: Are there really pictures in the brain? Trends in Cognitive Sciences, 7(3), 113-118. https://doi.org/10.1016/S1364-6613(03)00003-2

Prinz, J. J. (2002). Furnishing the mind: Concepts and their perceptual basis. Cambridge, MA: MIT Press. https://doi.org/10.7551/mitpress/3169.001.0001

Reisberg, D. (Ed.). (1992). Auditory Imagery. Hillsdale, NJ: Erlbaum.

Reisberg, D., Pearson, D. G., \& Kosslyn, S. M. (2003). Intuitions and introspections about imagery: the role of imagery experience in shaping an investigator's theoretical views. Applied Cognitive Psychology, 17, 147-160. https://doi.org/10.1002/acp.858

Rey, G. (1981). Introduction: What are Mental Images? In N. Block (Ed.), Readings in the Philosophy of Psychology (Vol. 2, pp. 117-127). Cambridge, MA: Harvard University Press.

Russell, B. (1919). On Propositions: What They Are and How They Mean. Aristotelian Society Supplementary Volume 2, 1-43. https://doi.org/10.1093/aristoteliansupp/2.1.1

Russell, B. (1921). The Analysis of Mind. London, UK: Allen \& Unwin.

Ryle, G. (1949). The Concept of Mind. London, UK: Hutchinson.

Rosch, E. (1975). Cognitive representations of semantic categories. Journal of Experimental Psychology: General, 104(3), 192-253. https://doi.org/10.1037/0096-3445.104.3.192

Sachs-Hombach, K. (2003). Das Bild als kommunikatives Medium: Elemente einer allgemeinen Bildwissenschaft. Köln, Germany: Herbert von Halem Verlag.

Sartre, J.-P. (1962). Imagination: A Psychological Critique. (F. Williams, Trans.). Ann Arbor: University of Michigan Press. (Original work published 1936) 
Schwartz, R. (1981). Imagery - There's More to it Than Meets the Eye. In N. Block (Ed.), Imagery (pp. 109-130). Cambridge, MA: MIT Press.

Scarry, E. (1999). Dreaming by the Book. Princeton, NJ: Princeton University Press.

Shepard, R. N., \& Chipman, S. (1970). Second-order Isomorphism of Internal Representations: Shapes of States. Cognitive Psychology, 1, 1-17. https://doi.org/10.1016/0010-0285(70)90002-2

Shepard, R. N., \& Metzler, J. (1971). Mental rotation of three-dimensional objects. Science, 171, 701-703. https://doi.org/10.1126/science.171.3972.701

Soles, D. (1999). Is Locke an Imagist? The Locke Newsletter, 30, 17-66.

Sonesson, G. (2008). Prolegomena to a general theory of iconicity. Considerations on language, gesture, and pictures. In K. Willems \& L. De Cuypere (Ed.), Naturalness and Iconicity in Language (pp. 47-72). Amsterdam, the Netherlands: John Benjamins Publishing Company. https://doi.org/10.1075/ill.7.05son

Stjernfelt, F. (2007). Diagrammatology: An Investigation on the Borderlines of Phenomenology, Ontology and Semiotics. Dordrecht, the Netherlands: Springer. https://doi.org/10.1007/978-14020-5652-9

Suchman, L. (1987). Plans and situated actions. Cambridge, UK: Cambridge University Press.

Thagard, P. (2005). Mind: Introduction to Cognitive Science. Cambridge, MA: MIT Press. https://doi.org/10.7551/mitpress/9218.001.0001

Thagard, P. (2012). The Cognitive Science of Science: Explanation, Discovery, and Conceptual Change. Cambridge, MA: MIT Press.

Thomas, N. J. T. (2003). Mental Imagery, Philosophical Issues About. In L. Nadel (Ed.), Encyclopedia of Cognitive Science (Vol. 2, pp. 1147-1153). London, UK: Nature Publishing.

Titchener, E. B. (1909). Lectures on the Experimental Psychology of the Thought-Processes. New York, NY: Macmillan. https://doi.org/10.1037/10877-000

Troscianko, E. T. (2010). Kafkaesque Worlds in Real Time. Language and Literature, 19, 151-171. https://doi.org/10.1177/0963947010362913

Troscianko, E. T. (2013). Reading Imaginatively: The Imagination in Cognitive Science and Cognitive Literary Studies. Journal of Literary Semantics, 42(2), 181-198. https://doi.org/10.1515/j1s-2013-0009

Troscianko, E. T. (2014). Kafka's Cognitive Realism. New York, NY: Routledge.

Tversky, B. (2001). Spatial schemas in depictions. In M. Gattis (Ed.), Spatial schemas and abstract thought (pp. 79-111). Cambridge, MA: MIT Press.

Tversky, B. (2004). Semantics, syntax, and pragmatics of graphics. In K. Holmqvist \& Y. Ericsson (Ed.), Language and visualization (pp. 141-158). Lund, Sweden: Lund University Press.

Tversky, B. (2011). Visualizing thought. Topics in Cognitive Science, 3, 499-535.

https://doi.org/10.1111/j.1756-8765.2010.01113.x 
Tversky, B., \& Lee, P. U. (1998). How space structures language. In C. Freksa, C. Habel, \& K. F. Wender (Ed.), Spatial Cognition: An interdisciplinary approach to representation and processing of spatial knowledge (pp. 157-175). Berlin, Germany: Springer. https://doi.org/10.1007/3-540-69342-4_8

Tversky, B., Lee, P. U. (1999). Pictorial and verbal tools for conveying routes. In C. Freksa \& D. M. Mark (Ed.), Spatial information theory: Cognitive and computational foundations of geographic information science (pp. 51-64). Berlin, Germany: Springer. https://doi.org/10.1007/3540-48384-5_4

Vallée-Tourangeau. F., Steffensen, S. V., Vallée-Tourangeau, G., \& Sirota, M. (2016). Insight with hands and things. Acta Psychologica, 170, 195-205. https://doi.org/10.1016/j.actpsy.2016.08.006

Watson, J. B. (1913). Psychology as the behaviorist views it. Psychological Review, 20, 158-177.

Watson, J. B. (1928). The Ways of Behaviorism. New York, NY: Harper. https://doi.org/10.1037/h0074428

Wittgenstein, L. (1953). Philosophical Investigations (2 ${ }^{\text {nd }}$ ed.). (G. E. M. Anscombe \& R. Rhees, Trans.). Oxford, UK: Blackwell.

Wollheim, R. (1984). The Thread of Life. Cambridge, UK: Cambridge University Press.

White, A. R. (1990). The Language of Imagination. Oxford, UK: Blackwell.

Wright, E. (1983). Inspecting Images. Philosophy, 58, 57-72. https://doi.org/10.1017/S0031819100056266

Yolton, J. W. (1996). Perception and Reality: A History from Descartes to Kant. Ithaca, NY: Cornell University Press.

Yoo, S.-S., Freeman, D. K., McCarthy J. J. III, \& Jolesz, F. A. (2003). Neural Substrates of Tactile Imagery: A Functional MRI Study. NeuroReport, 14(4), 581-585. https://doi.org/10.1097/00001756-200303240-00011

Zacks, J., \& Tversky, B. (2001). Event structure in perception and conception. Psychological Bulletin, 127, 3-21. https://doi.org/10.1037/0033-2909.127.1.3

The editorial and publishing process of this publication has been financed by the research grant "What is Thinking with Images?", SONATA 10, granted by the National Science Centre, Poland, on the basis of the decision No. 2015/19/D/HS1/02426. 